\title{
Evolutionary computation and genetic algorithms for designing the optimal mine haul road pavements
}

\author{
Anna Tailakova ${ }^{1 *}$, Alexander Pimonov ${ }^{1,2}$, and Daulet Mahambayev $^{3}$ \\ ${ }^{1}$ T.F. Gorbachev Kuzbass State Technical University, 650000 Kemerovo, 28 Vesennyaya st., Russian \\ Federation \\ ${ }^{2}$ Institute of Economics and Industrial Engineering, Siberian Branch of the Russian Academy \\ of Sciences, Novosibirsk, 630090 Novosibirsk, 17 Acad. Lavrentyev Av., Russian Federation \\ ${ }^{3}$ Kazakh Humanitarian Juridical Innovative University, Semey, 11 Mangilik el st., Kazakhstan
}

\begin{abstract}
An overview of the software for designing flexible road pavements used in the USA, European countries and the Russian Federation is given, conceptual and mathematical models for designing flexible road pavements with the minimum cost per a linear meter are presented, the application of evolutionary algorithms in combination with exhaustive search and parallel computing is substantiated, the developed hybrid genetic algorithm for the optimization of flexible road pavement designs in terms of value of materials of layers is described, the results of a simulation experiment performed using the software developed within the framework of the study are presented in the article. It is proposed to use the developed software and algorithms for designing the optimal haul road pavements in terms of material cost.
\end{abstract}

\section{Introduction}

The main processes of mining are rock excavation and haulage. The economic feasibility of haulage and the performance of heavy-duty trucks are largely determined by the state of haul roads. As a rule, haul roads are three-layer macadam pavements, the service life of which is 3-5 years. Temporary haul roads, the service life of which is several months, are also common. Improving road service quality and reducing the share of temporary roads will provide an increase in the performance of haul trucks and a decrease in fuel consumption [1-2].

The safety and reliability of road usage during the entire service life of a pavement is ensured by establishing and observing the appropriate design parameters, including indicators of strength, reliability and stability. The pavement design must meet the strength requirements for the design service life, for which road scientists from different countries have developed methods for estimating stresses, strains and deflections in representative sections and points of the structure. A number of regulatory documents have been developed on the basis of theoretical and experimental studies that allow designing flexible road pavements, taking into account the achievements of modern science [1].

Approaches based on empirical research or laboratory tests of soils and materials usually prevail among the quality assurance methods for designing flexible road pavements

* Corresponding author: taa.vtit $@$,kuzstu.ru 
common in the USA and European countries. The thicknesses of layers are determined based on the experience of implementing similar design solutions in similar climatic conditions. Modern methods for designing flexible road pavements combine empirical and theoretical approaches and involve a large amount of calculations, which are possible to perform only with the use of computer technology and appropriate software systems. Among the most popular software tools abroad are the following:

1. MnPAVE Flexible - software that uses a mechanical-empirical approach to predict the state of flexible road pavements. As a result, MnPAVE designs the expected pavement life, which is calculated using damage factor according to Miner's rule (linear damage accumulation for cyclic unsteady loading). Reliability is assessed by Monte Carlo simulations. The software includes a research module for analyzing the service life of layers of different thicknesses [3].

2. PerRoad - a system developed at the University of Auburn in the United States. This software uses layered elastic analysis (WESLEA) model as well as Monte Carlo simulation method to estimate stresses and strains in the road pavement [4].

3. AASHTOWare Pavement ME Design is a tool for public and private design organizations that allows calculating stresses, strains and deflections of road pavements, take into account factors such as traffic density, climate, material characteristics in order to predict the distresses of asphalt concrete pavements [5].

The software used abroad allows designing flexible road pavements in accordance with modern methods, work with material databases and predict the service life of a pavement.

In accordance with the regulatory documents in force in the Russian Federation, the procedure for designing flexible road pavements is a laborious process that requires taking into account a large number of environmental parameters, properties of materials and soils. In addition, it is necessary to save material and financial resources during road construction. The complexity of the calculations and a large amount of reference information suggest the advisability of using computer technology and software in the design process.

The task of designing flexible road pavements is reduced to the selection of the thicknesses of their layers or to the selection of materials with the appropriate stress-strain performance at the given layer thicknesses and taking into account the strength requirements.

The decision-making speed and efficiency can be significantly increased by taking into account many years of experience in observing the service life of pavements in various climatic zones. The use of the book of typical design solutions (hereinafter Typicals) in design organizations allows significant narrowing the range of search among the possible design options. The use of computing facilities provides the possibility to access the Typicals and an extensive base of building materials. However, it should be noted that empirical methods give satisfactory results only when the specific construction conditions correspond to the reference conditions of the previously constructed sections. Therefore, determining materials to be used and layer thicknesses, based on the recommendations given in the Typicals, still remains the task of a design specialist.

Today, there are various CAD software products that allow solving problems of designing flexible road pavements, including the optimal design selection:

1. «IndorPavement. Pavement design system». The system allows testing the pavement for strength according to various criteria and contains a number of templates of typical solutions for designing pavements. To select the optimal solution, the thickness of layers can be varied in automatic mode according to the specified criteria: price, strength, thickness.

2. «CREDO RADON 3.9». The RADON system performs automated design of flexible and rigid road pavements according to industry standards. The system allows selecting a structure of minimum thickness, least strength and minimum estimated cost. 
3. «TopomatikRobur - Road pevements» - software for designing and evaluating the strength of flexible and rigid road pavements. This software provides the possibility to maintain a database of materials, perform the automated brute-force search of the pavement layer thicknesses in predefined increments to select the optimal design.

The software tools considered above make it possible to search for the optimal design by selecting the thicknesses of layers using optimization methods, as well as by comparing the cost-performance ratio of designs obtained as a result of several calculations. But these software systems do not provide for the possibility of design optimization by varying the materials of layers.

The purpose of the presented study is the development, substantiation and software implementation of a mathematical optimization model and an algorithm for the numerical design of flexible road pavements, allowing to select them by varying the materials and the thicknesses of layers.

\section{Mathematical model for selecting the road pavement design with the minimum cost per a linear meter}

The majority of Russian practical methods for designing road pavements are based on theoretical models that make it possible to determine the compliance of the project with the criteria that ensure the required service life of the roadway. The theoretical task is to develop a mathematical model that allows studying the mechanical properties of the designed road pavement and predict the possible destruction of the road surface that occurs under the influence of the environment.

In accordance with the regulatory documents in force in the Russian Federation, a conceptual model for designing the cost-effective flexible road pavement can be proposed (Fig. 1). The input parameters of the model are: physical and engineering characteristics of soils, climatic characteristics of the terrain, road traffic density, expected road-service quality and a given service life, stress-strain, strength and cost performance of possible road building materials.

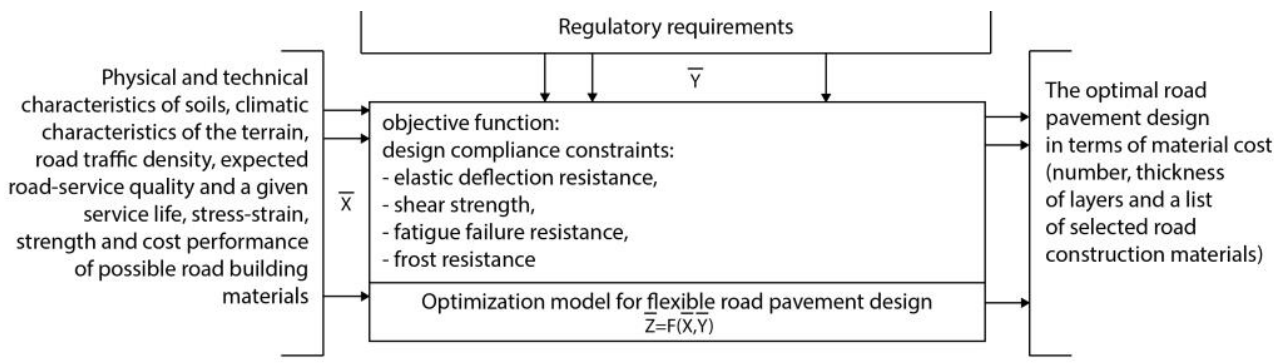

Fig. 1. Conceptual model for designing cost-effective flexible road pavements in terms of value of materials

To ensure the strength of the structure for a given service life, the following conditions must be met:

1. Condition of shear strength of the sub-grade and weakly cohesive layers:

$$
K_{\text {str }} \leq T_{\text {adm }} / T
$$

where $K_{\text {str }}$ - strength factor determined taking into account a given level of reliability; $T_{\text {adm }}-$ admissible shear stress due to soil cohesion; $T$ - active shear stress in soil or weakly cohesive material.

2. Condition of resistance of monolithic layers to bending tensile fatigue failure:

$$
K_{\text {пр }} \leq R_{\text {доп }} / \sigma_{r},
$$

where $R_{\mathrm{adm}}$ - maximum admissible tensile stress of the layer material, taking into account 
fatigue effect; $\sigma_{r}$ - highest tensile stress in the layer under consideration, found by calculation.

3. Condition of admissible elastic deflection resistance of the structure as a whole:

$$
K_{\text {пр }} \leq E_{\mathrm{TP}} / E_{\text {общ, }}
$$

where $E_{\text {total }}$ - total modulus of elasticity of the structure; $E_{\text {req }}$ - required modulus of elasticity of the structure, taking into account the degree of pavement durability and the load density.

In areas of seasonal freezing of sub-grades under unfavorable soil and hydrological conditions, along with the required strength and resistance, sufficient frost resistance must be provided:

$$
l_{\text {пуч }} \leq l_{\text {доп }}
$$

where $l_{\text {heave }}$ - calculated (expected) frost heave; $l_{\text {adm }}$ - admissible frost heave.

The construction cost of flexible road pavements consists of the construction costs and the cost of the materials for layers. The cost per a linear meter of construction $S$ can be determined by the formula:

$$
S=\sum_{i=1}^{n} c_{i} h_{i}
$$

where $h_{i}$ - the $i$-th layer thickness; $c_{i}$ - the cost of $1 \mathrm{~m}^{2}$ of the material of $i$-th layer; $n$ - the number of layers [2].

As a result of formalizing the proposed conceptual model, a mathematical model for designing flexible road pavement was obtained, the constraints of which (1)-(4) are dictated by the requirements of regulatory documents, and the objective function $S$ is the cost of a linear meter of the pavement (5). Unknown quantities are the thicknesses and the materials of layers. The minimum thicknesses of layers and the variability intervals are regulated by regulatory documents. The materials of layers are varied on the basis of the Typicals:

$$
S\left(h_{1}, t_{1}, h_{2}, t_{2}, \ldots, h_{n}, t_{n}\right) \rightarrow \min _{h_{i}, t_{i}}
$$

under constraints:

$$
\left\{\begin{array}{l}
f_{1}\left(h_{1}, t_{1}, h_{2}, t_{2}, \ldots, h_{n}, t_{n}\right) \geq k_{1} \\
f_{2}\left(h_{1}, t_{1}, h_{2}, t_{2}, \ldots, h_{n}, t_{n}\right) \geq k_{2} \\
f_{3}\left(h_{1}, t_{1}, h_{2}, t_{2}, \ldots, h_{n}, t_{n}\right) \geq k_{3} \\
f_{4}\left(h_{1}, t_{1}, h_{2}, t_{2}, \ldots, h_{n}, t_{n}\right) \geq k_{4} \\
h_{i} \in H_{i} \\
t_{i} \in T_{i} \\
n>3
\end{array}\right.
$$

where $k_{1}$ - factor of shear strength of the sub-grade and weakly cohesive layers (1); $f_{1}\left(h_{1}, t_{1}, h_{2}, t_{2}, \ldots, h_{n}, t_{n}\right)$ - ratio of admissible shear stress to active shear stress $T_{\text {adm }} / T(1)$; $k_{2}$ - factor of resistance of monolithic layers to bending tensile fatigue failure (2); $f_{2}\left(h_{1}, t_{1}, h_{2}, t_{2}, \ldots, h_{n}, t_{n}\right)$ - ratio of the maximum admissible tensile stress to the maximum tensile stress in the layer under consideration $R_{\text {adm }} / \sigma_{r}(2) ; k_{3}$ - elastic deflection resistance factor $(3) ; f_{3}\left(h_{1}, t_{1}, h_{2}, t_{2}, \ldots, h_{n}, t_{n}\right)$ - ratio of the required modulus of elasticity of the structure to the total modulus of elasticity $E_{\text {req }} / E_{\text {total }}(3) ; k_{4}$-admissible frost heave (4); $f_{4}\left(h_{1}, t_{1}, h_{2}, t_{2}, \ldots, h_{n}, t_{n}\right)$ - calculated (expected) frost heave (4); $S\left(h_{1}, t_{1}, h_{2}, t_{2}, \ldots, h_{n}, t_{n}\right)-$ cost of one linear meter of construction (5); $h_{i}$ - the $i$-th layer thickness; $H_{i}$ - the admissible $i$-th layer thicknesses; $t_{i}-$ the $i$-th layer material; $T_{i}$ - admissible materials for $i$-th layer; $n-$ number of pavement layers.

Thus, a mathematical model is proposed for selecting the road pavement design with the minimum cost of a linear meter. Designing cost-effective flexible road pavements is a 
discrete optimization problem (6)-(7) with nonlinear constraints, which cannot be solved analytically.

\section{Application of evolutionary computation for the optimization of flexible road pavement design selection}

An exhaustive search of solutions guarantees finding the global minimum. But the running time of an exhaustive search algorithm exponentially depends on the dimension of the problem. It is possible to speed up this algorithm by using the parallel computing technology. In the best case, the speed of an algorithm increases in proportion to the number of threads.

Thus, direct search methods, despite the guarantee of finding the global optimum, may not be time efficient. Heuristic methods are more efficient for solving various optimization problems. Algorithms based on these methods allow working with both continuous and discontinuous objective functions, taking into account a large number of problem constraints. These algorithms are easy to parallelize and allow solving combinatorial problems [6-8].

The corresponding software was developed for the computational experiment. The developed software toolkit allows determining a design scheme for designing flexible road pavements in accordance with the Typicals, to calculate the strength of road pavements according to the following criteria: criterion of shear strength of the sub-grade and weakly cohesive layers, criterion of resistance of monolithic layers to bending tensile fatigue failure, criterion of elastic deflection of the structure, and also carry out a frost resistance test (1)-(4); allows searching for the cost-effective design of flexible road pavements by varying the materials and the thicknesses of layers (6)-(7) using an exhaustive search of solutions and heuristic optimization methods.

To carry out a computational experiment, a design scheme for flexible heavy-duty road pavements for climatic zone III, containing 5 layers, was used. Materials and thicknesses of layers are determined in accordance with the Typicals.

Computational experiments were carried out using equipment with the following characteristics: processor Intel(R) Core(TM) i5-4210U CPU $1.70 \mathrm{GHz} 2.4 \mathrm{GHz}$; total number of cores - 2, threads - 4; RAM 6.00 GB (5.9 GB available); system type - 64-bit operating system, x64 processor Windows-10; Apache virtual server; MySQL 5.5, phpMyAdmin 3.5.1.

Table 1. Results of the work of genetic algorithms with various modifications

\begin{tabular}{|l|c|c|c|c|}
\hline & $\begin{array}{c}\text { Canonical } \\
\text { genetic } \\
\text { algorithm }\end{array}$ & $\begin{array}{c}\text { Elitism } \\
\text { selection }\end{array}$ & $\begin{array}{c}\text { Steady state } \\
\text { selection }\end{array}$ & $\begin{array}{c}\text { Hybrid } \\
\text { algorithm }\end{array}$ \\
\hline $\begin{array}{l}\text { Average deviation of the } \\
\text { result from the optimal } \\
\text { value (\%) }\end{array}$ & 24,38 & 3,12 & 0,37 & 0,39 \\
\hline Average running time (s) & 51 & 47.9 & 36.17 & 18.37 \\
\hline $\begin{array}{l}\text { Average number of designs } \\
\text { considered }\end{array}$ & 10000 & 10000 & 3840 & 1815 \\
\hline $\begin{array}{l}\text { Average number of accesses } \\
\text { to the objective function }\end{array}$ & 6738 & 1332 & 3809 & 226 \\
\hline Average amount & 100 & 100 & 38.4 & 18.15 \\
\hline
\end{tabular}


To design the cost-effective flexible road pavements, it is proposed to use a genetic algorithm. Genetic algorithm is based on an evolutionary search method that can be flexibly configured [9-15]. To carry out a computational experiment, 100 runs of each genetic algorithm modification were considered [1]. As part of the experiment, various modifications of genetic algorithm were considered (Table 1) and it was found that to solve the set problem, it is advisable to use genetic algorithm with the following modifications:

1. Variants of flexible road pavement design are presented in the form of chromosomes that make up the population, genes are the parameters of layers (material and thickness of a layer), coding is carried out in integers, since the parameters are discrete.

2. The first population is uniformly distributed to cover the largest possible search space.

3. A new generation is formed by steady state selection.

4. The algorithm stops when the population converges or when the specified maximum number of generations is reached.

One of the problems of applying evolutionary computations to optimize multiextremal functions is getting into a local extremum. To solve this problem, it is possible to use hybrid genetic algorithms. The advantage of genetic algorithms is the possibility to combine them with other optimization methods. A common approach is the inclusion of nonlinear programming methods into genetic algorithm for local optimization of chromosomes [1, 9-15].

The proposed genetic algorithm for the local optimization uses an exhaustive search. When forming a new population, all new variants of design are optimized using an exhaustive search and only then are included into the new population. The next shift of the chromosome is carried out based on the calculation of the Euclidean distance. This approach combines the possibility to consider a variety of solution options with the accuracy of exhaustive search methods to achieve faster convergence and increase the reliability of the algorithm.

The use of genetic algorithm allows getting good solutions for an acceptable time of work. It should be noted that the accuracy of the algorithm can be increased by increasing the population size, but the running time of the algorithm will also increase. Parallel run of genetic algorithm allows obtaining high accuracy with less calculation time (Table 2).

Table 2. Results of the work of hybrid genetic algorithm

\begin{tabular}{|l|l|l|}
\hline & $\begin{array}{l}\text { Hybrid genetic algorithm } \\
\text { (400 chromosomes in a } \\
\text { population) }\end{array}$ & $\begin{array}{l}\text { Hybrid genetic algorithm } \\
\left(\begin{array}{l}\text { Run in phromosomes). } \\
\text { processes })\end{array}\right.\end{array}$ \\
\hline $\begin{array}{l}\text { Average deviation of the result from } \\
\text { the optimal value (\%) }\end{array}$ & 0,026 & 0.021 \\
\hline Average running time (s) & 234 & 74.9 \\
\hline $\begin{array}{l}\text { Average number of designs } \\
\text { considered }\end{array}$ & 9408 & 9500 \\
\hline
\end{tabular}

The developed software makes it possible to the design flexible road pavements in accordance with the regulatory documents adopted in the Russian Federation, as well as to select the optimal design by varying the thicknesses and the materials of layers, since due to the use of the proposed hybrid genetic algorithm and parallel computing technology, it becomes possible to analyze a large number of design options for flexible road pavements in an acceptable time 
Software developed using parallel computing technology based on the proposed model and a genetic algorithm for numerical design of flexible road pavements allows reducing labor costs and time of work on a project, as well as reducing error rate when designing in comparison with the traditional method.

\section{Conclusions}

Improvement of methods for designing haul road pavements is necessary to reduce the cost of building and maintaining roads, as well as to increase the performance of haul trucks. The selection of the optimal design of flexible road pavements is a laborious iterative process that requires the use of mathematical modeling and optimization methods using modern computer technology and software systems.

An increase in available building materials, the amount of calculations to select the cost-effective design lead to an exponential growth in the amount of exhaustive searches of variants. Thus, it is advisable to use mathematical optimization methods to ensure the efficiency of the work of road specialists getting rid of time-consuming routine operations when designing flexible road pavements.

The following results of the study are obtained:

1. A mathematical model (6)-(7) is proposed for designing flexible road pavements.

2. To solve this optimization problem, a numerical method based on a combination of evolutionary search and exhaustive search was developed, which makes it possible to obtain designs that are minimal in cost and meet the requirements of strength and frost resistance by varying the thicknesses and (or) materials of layers.

3. Various modifications of a genetic algorithm are considered to solve the set optimization problem. A hybrid genetic algorithm based on the proposed numerical method has been developed.

4. The efficiency of application of evolutionary algorithms in combination with an exhaustive search and parallel computations for the optimization of the design of flexible road pavements in terms of value of materials of layers has been substantiated.

5. Using the parallel computing technology, an original software has been developed, which includes the proposed mathematical model and an algorithm for searching the optimal design of flexible road pavements.

\section{References}

1. A. Tailakova, A. Pimonov, E3S Web of Conferences, 134, 01007 (2019)

2. V. Shalamanov, S. Shabaev, F. Alama, E3S Web of Conferences, 134, 01013 (2019)

3. MnPAVE User's Guide. (Minnesota Department of Transportatio, 2012)

4. H. Behbahani, A.M. Khaki, A.A. Amini. Assessment of Perpetual Pavement Performance using Mechanistic-Empirical Pavement Design Guide (M-E PDG) and PerRoad Software Models. (International Conference on Perpetual, Columbus, Ohio, 2009)

5. AASHTOWare Pavement ME User Manual. (Virginia Department of Transportation Pavement Design and Evaluation Section Central Office, Materials Division, 2017)

6. R. Impagliazzo. 10th Annual Structure in Complexity Theory Conference (SCT'95). A personal view of average-case complexity, 134 (1995)

7. R. Marti, Celso C. Ribeiro, Mauricio G.C. Resende. European Journal of Operational Research. Multi-start methods for combinatorial optimization, 226(1), 1 (2013) 
8. R. Marti, R. Aceves, M.T. Leon, J.M. Moreno-Vega, and A. Duarte, International Series in Operations Research \& Management Science. Intelligent Multi-Start Methods, 272(2018)

9. A. Laaksonen. Competitive Programmer's Handbook, (2018)

10. D. Bednárek, M. Brabec, M. Kruliš. Information Systems. Improving matrix-based dynamic programming on massively parallel accelerators, 64, 175 (2017)

11. K. Oliver. Genetic Algorithm Essentials. Studies in Computational Intelligence, 679 (2017)

12. E.V. Vasileva, V.S. Doroganov, A.B. Piletskaya, et al. Coke and Chemistry. Predicting the Yield of Coking Products, 60:9, 356 (2017)

13. E.V. Vasileva, V.S. Doroganov, A.B. Piletskaya, et al. Coke and Chemistry. Estimation of the Yield of Coking Productsby a Neural-Network Model, 62:2, 47 (2019)

14. E.V. Vasileva, V.S. Doroganov, A.B. Piletskaya, et al. Coke and Chemistry. Neural-Network Model for Predicting the Yield of Coking Products, 62:2, 40 (2019)

15. S. Ganjefar, M. Tofighi. Engineering Applications of Artificial Intelligence. Training qubit neural network with hybrid genetic algorithm and gradient descent for indirect adaptive controller design, $\mathbf{6 5}, 346$ (2017) 